\title{
Thin ink-jet printed trilayer actuators composed of PEDOT:PSS on interpenetrating polymer networks
}

\author{
Inga Põldsalua ${ }^{a}$, Kätlin Rohtlaid ${ }^{\mathrm{b}}$, Tran Minh Giao Nguyen ${ }^{\mathrm{b}}$, Cedric Plesse ${ }^{\mathrm{b}}$, \\ Frédéric Vidal $^{\mathrm{b}}$, Mahdi Safaei Khorram ${ }^{\mathrm{c}}$, Anna-Liisa Peikolainen ${ }^{\mathrm{a}}$, Tarmo Tammª \\ Rudolf Kiefer $^{\mathrm{d}, *}$ \\ a Intelligent Materials and Systems Lab, Institute of Technology, University of Tartu, Nooruse 1, 50411 Tartu, Estonia \\ ${ }^{\mathrm{b}}$ Laboratoire de Physicochimie des Polymères et des Interfaces, Université de Cergy-Pontoise, Cergy, France \\ ' State Key Laboratory of Organic Geochemistry, Guangzhou Institute of Geochemistry, Chinese Academy of Sciences, 511 Kehuajie, Guangzhou 510640, \\ China \\ d Conducting polymers in composites and applications Research Group, Faculty of Applied Sciences, Ton Duc Thang University, Ho Chi Minh City, Vietnam
}

\section{A R T I C L E I N F O}

\section{Article history:}

Received 22 August 2017

Received in revised form

16 November 2017

Accepted 23 November 2017

Available online 29 November 2017

\section{Keywords:}

Aqueous and organic electrolyte

Bending actuation

Inkjet-printing

Linear actuation

PEDOT:PSS-IPN

Thin films

\begin{abstract}
A B S T R A C T
Mass production of conducting polymer actuators with reliable performance is envisaged in the field of artificial muscles. In this study, inkjet printing and spin coating - two established technologies for large-scale production - were combined for microactuator fabrication. Actuators based on poly(3,4ethylenedioxy-thiophene):poly(styrene sulfonate) electrodes (PEDOT:PSS, $2.2 \mu \mathrm{m}$ thick, $190 \mathrm{~S} \mathrm{~cm}^{-1}$ ), which were inkjet-printed onto a spin-coated membrane of an interpenetrating polymer network (IPN) thin film composed of nitrile butadiene rubber and poly(ethylene oxide) (PEDOT:PSS-IPN-PEDOT:PSS) with a total thickness of $12.7 \mu \mathrm{m}$, were prepared and studied. Our goal was to investigate the performance of the trilayers in linear actuation, in aqueous and organic (propylene carbonate) solutions of bis(trifluoromethane)sulfonimide lithium salt (LiTFSI) used as electrolytes, and in bending actuation in air using an ionic liquid as the electrolyte. Electro-chemo-mechanical deformation (ECMD) measurements were consistent with electrochemical measurements showing a strain of $3 \%$ in aqueous electrolyte and $1 \%$ in propylene carbonate. A strain of $0.14 \%$ in the bending mode in the ionic liquid was observed due to electric double layer charging, while in electrolyte solutions, redox reactions determined the linear actuation properties. In the aqueous electrolyte, a specific capacitance of $193 \mathrm{Fg}^{-1}$ was measured for the printed PEDOT:PSS films, with potential for applications in supercapacitors.
\end{abstract}

(c) 2017 Elsevier B.V. All rights reserved.

\section{Introduction}

In recent years, the development of new materials and devices that emulate natural muscles has attracted considerable attention, with the need to improve electromechanical behavior [1-7], realize new materials [8], enhance the fabrication process [9-13], and accomplish miniaturization [14-17]. Ionic electroactive polymer (iEAP)-based artificial muscles are becoming a promising alternative to conventional actuators in medicine, soft robotics [18-20], lab-on-a-chip devices [21], etc. due to their low power-to-mass ratio [22], softness and biocompatibility [23], and small dimensions [24].

\footnotetext{
* Corresponding author.

E-mail address: rudolf.kiefer@tdt.edu.vn (R. Kiefer).
}

Electronic conductive polymers (ECPs), such as poly(3,4ethylenedioxythiophene) (PEDOT) and polypyrrole, are ionic electroactive polymers. Such materials have some important advantages over the other types of electroactive polymer materials such as dielectric elastomers and ferroelectric polymers, including low driving voltage, inherent electrical conductivity, passively maintained tension (catch-states), and well reproducible and widely tunable properties $[25,26]$. The main operation principle of ECPs is based on redox-reactions that create mobile charges, inducing counter-ion flux, which leads to a reversible volume change that drives the actuation properties. Large anions such as PSS or dodecyl sulphonates remain immobile in the ECP network, leading to cation incorporation during reduction, which induces the volume change [23].

Conducting polymer-IPN electromechanical systems using nitrile butadiene rubber and poly(ethylene oxide) (NBR/PEO) have previously been synthesized on the macro-[12] and micro-scale 
[15,16]. Direct electrochemical [25] and chemical [27] polymerization of PEDOT onto the membrane enables homogeneous coverage of large areas; however, for microfabrication, generally a multiple-step subtractive technique such as photolithography is used $[17,28]$.

In this study, conducting polymer based ionic electroactive polymer composites are fabricated by combining spin-coating [15] and inkjet printing technologies $[10,29]$. Novel thin poly $(3,4-$ ethylenedioxy-thiophene):poly(styrene sulfonate)-nitrile butadiene rubber/poly-(ethylene oxide) PEDOT:PSS-NBR/PEO trilayer devices were built and characterized as linear and bending actuators, with particular focus on the effect of the solvent on the performance of the actuators.

In the linear actuation mode, instead of using 2.2-um-thick ECP free-standing films, the electromechanical properties of the trilayers were analyzed to demonstrate that the same trilayer configuration can be used for both bending and linear actuation.

The development of fabrication methods based on printing or coating technologies is of interest for the consistent industrialscale manufacturing of thin trilayer bending actuators that deliver economic use of the precursor material with high reproducibility.

In linear mode, electro-chemo-mechanical-deformation (ECMD) measurements coupled with cyclic voltammetry and chronopotentiometry were used to determine the electrochemical behavior and charge-strain dependency, as well as to calculate the diffusion coefficients. The performance of the trilayers in the bending mode was investigated by measuring the displacement of the actuator, which enables one to demonstrate the different actuation modes available in the same configuration.

\section{Material and methods}

\subsection{Fabrication of a 50-50 NBR/PEO solid polymer electrolyte membrane}

Semi-Interpenetrating Polymer Network (semi-IPN) solid polymer electrolytes were synthesized following Maziz et al. [15]. An aqueous solution of $300 \mathrm{~g} \mathrm{~L}^{-1}$ of polyvinyl alcohol (PVA, Aldrich, $\mathrm{Mw}=6000 \mathrm{~g} \mathrm{~mol}^{-1}$ ) was prepared by adding PVA to distilled water in a covered beaker before mixing overnight at $60^{\circ} \mathrm{C}$. A PVA sacrificial layer was spin coated $\left(1500 \mathrm{rpm} / 750 \mathrm{rpm} \mathrm{s}^{-1} / 15 \mathrm{~s}\right)$ onto a microscope slide and dried at $80^{\circ} \mathrm{C}$ for $5 \mathrm{~min}$ (Scheme $1 \mathrm{a}$ ). Nitrilebutadiene rubber (NBR, Lanxess, Germany) solution (17 wt\%) was prepared by dissolving NBR in cyclohexanone (Aldrich, $>99.8 \%$ ), which was left to stir overnight until complete dissolution. Poly(ethylene oxide) (PEO) (50 wt\% vs NBR) consisting of poly(ethylene glycol) dimethacrylate (PEGDM, Aldrich, $\mathrm{M}_{\mathrm{n}}=750 \mathrm{~g} \mathrm{~mol}^{-1}$ ) (25 wt\% of PEO network) and poly(ethylene glycol) methacrylate (PEGM, Aldrich, $\mathrm{M}_{\mathrm{n}}=500 \mathrm{~g} \mathrm{~mol}^{-1}$ ) ( $75 \mathrm{wt} \%$ of PEO network) was added to the previously prepared NBR solution and stirred for $30 \mathrm{~min}$. Dicyclohexyl peroxidicarbonate (DCPD, Groupe Arnaud, France) (3 wt\% of PEO network), as an initiator for the PEO network, was also added to the same solution, which was stirred for another $30 \mathrm{~min}$ and then degassed. A 50-50 NBR/PEO solution was spin coated ( $3000 \mathrm{rpm} / 3000 \mathrm{rpm} \mathrm{s}^{-1} / 30 \mathrm{~s}$ ) onto the top of the PVA sacrificial layer (Scheme 1b). Generally, solution viscosity, spinning speed, and spinning time determine the thickness of a spin-coated polymer film $[15,30]$. These parameters were adjusted to obtain a polymer film with a thickness of approximately $6 \mu \mathrm{m}$. Spin-coated films were placed in a heating bell under argon and cured for $4 \mathrm{~h}$ at $50{ }^{\circ} \mathrm{C}$ to initiate polymerization of the methacrylate derivatives in the presence of DCPD. After polymerization, semi-IPN layers were obtained, where the PEO network promotes ionic conductivity and the linear NBR imparts rubber-like properties to the membrane.

\subsection{Actuator fabrication}

Clevios $^{\mathrm{TM}}$ P Jet 700 PEDOT:PSS ink in aqueous solution (solids content 0.6-1.2 wt\%, Heraeus Precious Metals GmbH \& Co, Germany) was filtrated through syringe filters (Minisart ${ }^{\circledR} \mathrm{NML}$ Syringe Filters $17594-\mathrm{K}$ ) with a $5-\mu \mathrm{m}$ pore size. Inkjet printing was carried out using a jetlab ${ }^{\circledR}$ II Precision Printing Platform equipped with a PH-46 drop-on-demand printhead (MicroFab Ltd., U.S.A.) and a piezo-electrically driven MJ-AT-01 dispensing device with an orifice diameter of $50 \mu \mathrm{m}$. The jetting frequency was $800 \mathrm{~Hz}$, with a customized waveform. The temperature of the substrate holder was set to $45^{\circ} \mathrm{C}$ to enhance the evaporation of the solvent. Patterns were designed using the vector graphics software Inkscape (http://inkscape.org) and exported in a bitmap monochrome format to be uploaded by the printer software. The color space used for all images was binary, with white pixels corresponding to singleejection events.

PEDOT:PSS ink was printed onto the spin-coated NBR/PEO membrane by successively printing 10 layers directly on top of each other (Scheme 1c). The composite was thereafter additionally dried in a vacuum oven at 1 mbar pressure and at room temperature to obtain a solid polymer film, which was then left submerged in a water reservoir overnight, with the printed side facing downwards towards a Teflon collection sheet, to enable dissolution of the PVA layer (Scheme $1 \mathrm{~d}$ ). The microscope glass was carefully removed and the water was pipetted out to enable the membrane to flatten out on the supporting Teflon surface. After drying the sample in a vacuum oven at room temperature for $3 \mathrm{~h}$, 10 layers of PEDOT:PSS were printed onto the other (flipped) side of the membrane; these layers were aligned with the first electrode layer on the opposite side of the membrane (Scheme 1e,f). Trilayer actuators were cut out from the membrane using a scalpel without touching the electrodes to avoid a short circuit.

$0.2 \mathrm{M}$ bis(trifluoromethane)sulfonimide lithium salt (LiTFSI, 99.95\%, Solvionic, France) solution in water, 0.2 M LiTFSI in propylene carbonate (PC, $\geq 99 \%$, Sigma-Aldrich) and ionic liquid 1-ethyl-3-methylimidazolium bis(trifluoromethylsulfonyl)imide (EMImTFSI, 99.9\%, Solvionic, France) were used as electrolytes.

\subsection{ECMD measurements}

The PEDOT:PSS-semi-IPN trilayers (thickness $12.7 \mu \mathrm{m}$ ) were prepared with dimensions of $1.3 \mathrm{~cm} \times 0.1 \mathrm{~cm}$ (mass: $91 \pm 8 \mu \mathrm{g}$ ) and $0.7 \mathrm{~cm} \times 0.1 \mathrm{~cm}$ (mass: $49 \pm 4 \mu \mathrm{g}$ ) for measurements in LiTFSI-PC and LiTFSI-aq electrolyte, respectively. The trilayers were clamped onto an ECMD setup [31] and connected as a single working electrode, with Pt used as the counter electrode and $\mathrm{Ag} / \mathrm{AgCl}(3 \mathrm{M} \mathrm{KCl})$ as the reference electrode in $0.2 \mathrm{M}$ LiTFSI aqueous or propylene carbonate solution. Cyclic voltammetry measurements (scan rate $5 \mathrm{mV} \mathrm{s}^{-1}$ ) and the application of square-wave potential steps in the voltage range $0.65 \mathrm{~V}$ to $-0.6 \mathrm{~V}$ at frequencies $0.0025 \mathrm{~Hz}-0.1 \mathrm{~Hz}$ were carried out under isotonic ECMD measurement conditions (constant force of $4.9 \mathrm{mN}$ ). Integration of the square-wave current density gives the total consumed charge density $Q$ at any oxidation (reduction) time $\left(Q_{t}\right)$. As described in previous investigations [32], one can use the calculated charge density and Eq. (1) to determine the slope $b$.

$\ln \left[1-\frac{Q}{Q_{t}}\right]=-b t$

Therefore, the diffusion coefficient $\mathrm{D}$ can be calculated from Eq. (2), given the thickness $h$ of the electrode.

$D=\frac{b * h^{2}}{2}$ 


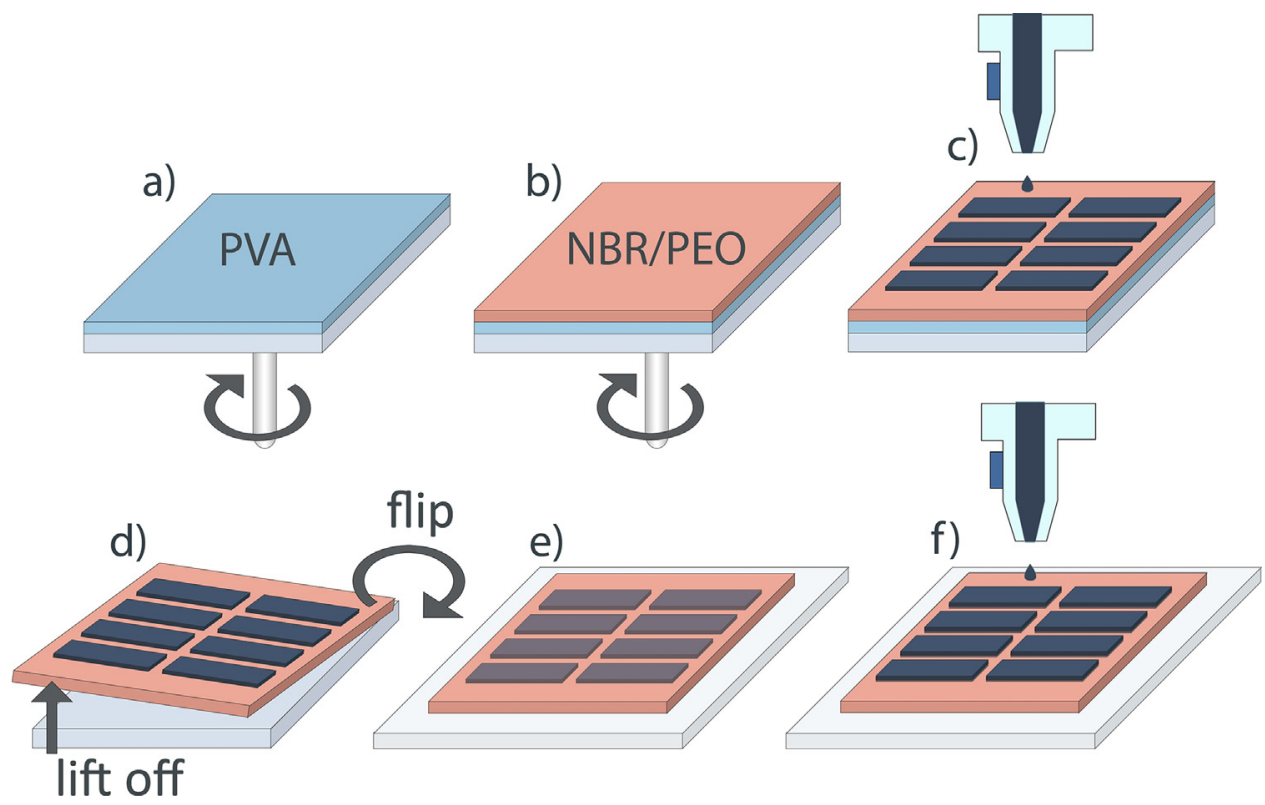

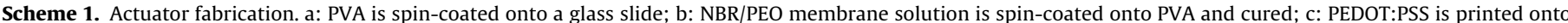

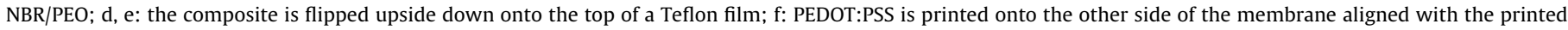
electrodes on the opposite side.

Chronopotentiometric measurements of PEDOT:PSS-IPN trilayers were carried out at frequencies ranging from $0.1 \mathrm{~Hz}-0.0025 \mathrm{~Hz}$ for a constant charge density of $33 \mathrm{mC} \mathrm{cm}^{-2}$.

\subsection{Bending displacement of PEDOT:PSS-IPN}

A PEDOT:PSS-IPN trilayer with dimensions of $20 \mathrm{~mm} \times 2 \mathrm{~mm}$ (thickness of $12.7 \mu \mathrm{m}$ ) was immersed in EMImTFSI. Strain measurements were carried out using an in-house setup consisting of a National Instruments PCI-6036E analog input DAQ and laser displacement meter LK-G82/LK-G3001P (Keyence). The actuators were mounted side-ways between flat gold contacts before a mirrored logarithmic sweep sine signal $(0.0025-0.1 \mathrm{~Hz}, \pm 0.6 \mathrm{~V})$ was applied to obtain the resonance frequency. Strain measurements were carried out at applied frequencies ranging from $0.0025 \mathrm{~Hz}$ to $0.1 \mathrm{~Hz}$ in a potential range of $\pm 0.6 \mathrm{~V}$. The displacement was measured at a $5 \mathrm{~mm}$ distance from the contacts. The strain difference between the electrodes was calculated from the displacement signal using Eq. (3) [2]:

$\varepsilon=\frac{2 * d * h}{L^{2}+d^{2}} * 100 \%$

where $\varepsilon$ is the strain difference, $\mathrm{d}$ is half of the peak-to-peak displacement, $\mathrm{h}$ is the thickness of the actuator, and $\mathrm{L}$ is the measurement distance from the fixed input contacts.

\subsection{Characterization of PEDOT:PSS-IPN}

A cross section of the PEDOT:PSS-IPN was studied using scanning electron microscopy (SEM, Helios NanoLab 600, FEI) coupled with energy dispersive X-ray (EDX) spectrometry to determine the thickness of the actuator and, based on the sulfur signal intensity, the thickness of the PEDOT:PSS layers. A four-point probe SRM232-2000 (Guardian Manufacturing, USA) was used together with in-house flat gold contacts to measure the surface resistivity of the printed electrodes. Sheet conductivity $\sigma_{\mathrm{s}}$ (Eq. (4)) was calcu- lated according to Heraeus Precious Metals GmbH \& Co [33], where $R_{S}$ is the sheet resistivity and $h$ the thickness of the electrode:

$\sigma_{S}=\frac{1}{R_{S} * h}$,

\section{Results and discussion}

\subsection{Characterization of the trilayer}

From the SEM image of the cross section of the actuator in Fig. 1a, one can distinguish the semi-IPN membrane layer (thickness of $10.4 \pm 1.8 \mu \mathrm{m}$ ) and PEDOT:PSS layers (with thickness of $2.2 \pm 0.66 \mu \mathrm{m}$ ) on both sides, as confirmed by EDX analysis (Fig. 1b). The mass of one dry PEDOT:PSS electrode (with dimensions $2 \mathrm{~cm} \times 0.2 \mathrm{~cm}$ ) was $140 \pm 8 \mu \mathrm{g}$. The surface conductivity of the printed PEDOT:PSS electrodes was $192 \pm 18 \mathrm{~S} \mathrm{~cm}^{-1}$, which is similar to that of PEDOT:PSS electrodes fabricated in a roll-to-roll process, $220 \mathrm{~S} \mathrm{~cm}^{-1}$, for flexible solar cells [34].

\subsection{Isotonic ECMD measurements of linear actuation}

\subsubsection{Cyclic voltammetry}

Most studies of actuators based on a trilayer design with inkjetprinted conducting polymer electrodes have been conducted by evaluation of the bending mode in air using ionic liquids as nonvolatile electrolytes [10]. However, little attention has been paid to the role of the electrolyte solution in such devices. In this study, the effect of solvent on the actuation of a PEDOT:PSS-IPN trilayer was investigated in the linear mode, with samples immersed in electrolyte in a three-electrode configuration. It has been found previously that the solvent can affect the extent of strain and even change the type/direction of actuation between anion and cation driven states [35]. The linear length change of the actuator in aqueous and organic electrolyte solutions was measured and compared under cyclic voltammetry control (Fig. 2).

A 3\% strain for the PEDOT:PSS-IPN trilayer in an aqueous electrolyte was achieved using mainly cation $\left(\mathrm{Li}^{+}\right)$driven actuation at reduction, with minor anion incorporation at oxidation (Fig. 2a). 

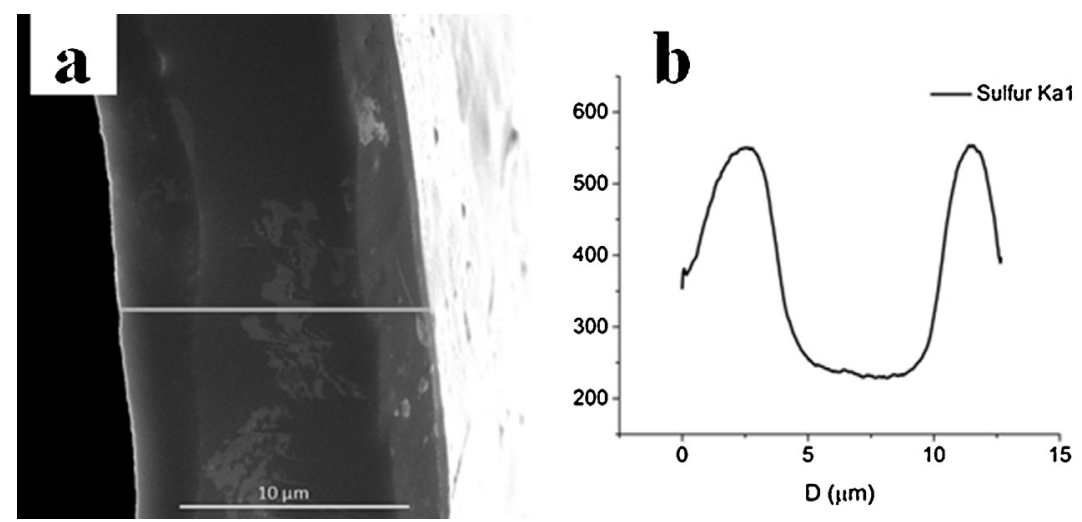

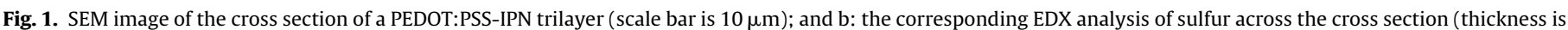
$12.7 \mu \mathrm{m})$.
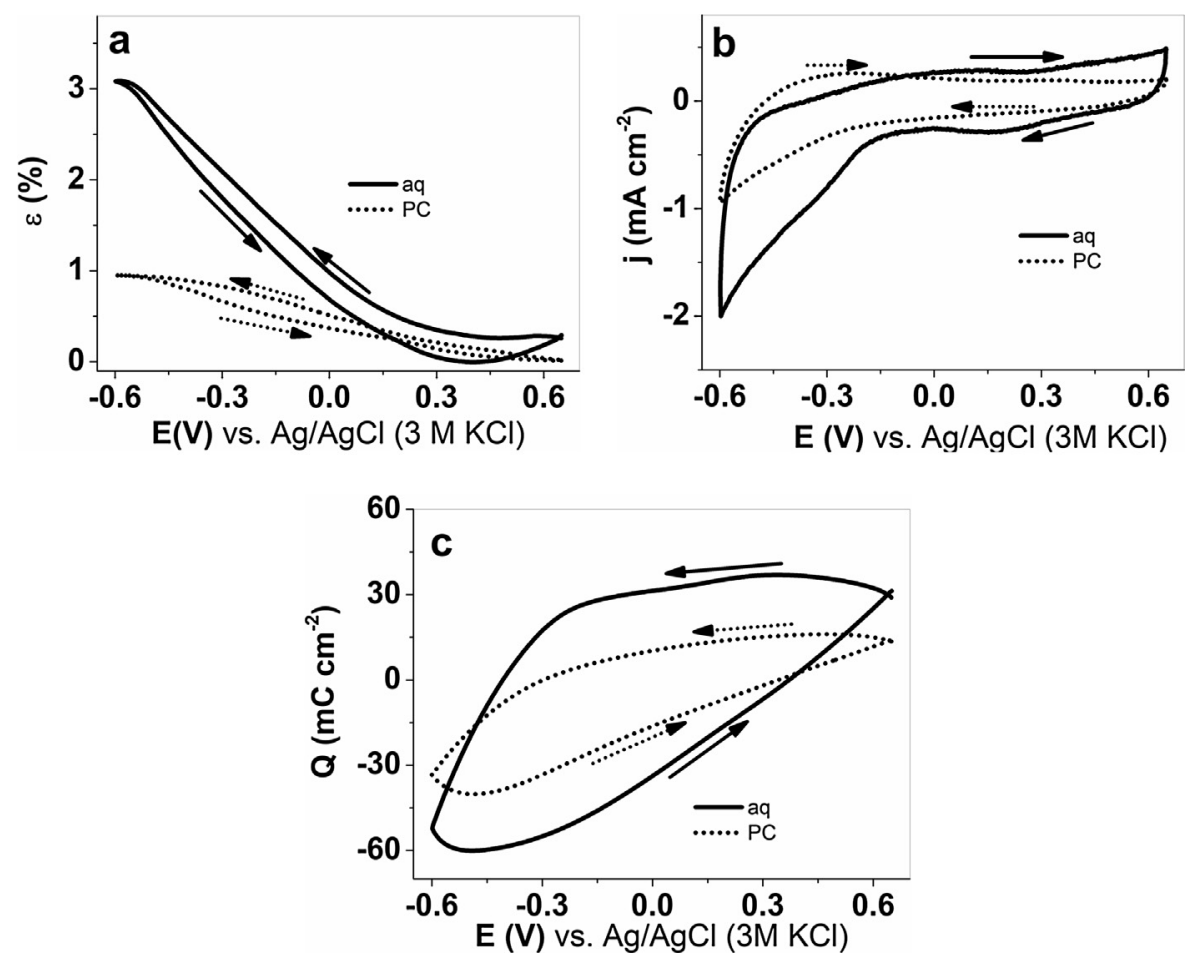

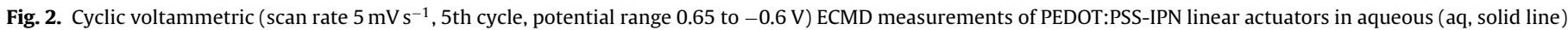
and propylene carbonate (PC, dotted line) LiTFSI $(0.2 \mathrm{M})$ solutions. a: strain $\varepsilon$ vs. potential, b: current density j vs. potential, and c: charge density $\mathrm{Q}$ vs. potential.

In an organic electrolyte solution, the strain reached $1 \%$. A similar trilayer configuration has been studied previously but using a more rigid PVdF membrane [29], where the strain only reached $0.2 \%$. Contrary to a previous study of electrochemically polymerized conducting polymers, where actuation direction changed with changing the solvent [35], the PEDOT:PSS-IPN trilayer shows expansion at reduction independent of the solvent. For both solvents, the main feature observed in the cyclic voltammograms is a large wave at large negative potentials, corresponding to a flux of cations [36]. Due to the chosen scan rate feasible for actuation, the wave is not quite a clearly formed peak (Fig. 2b). In case of the aqueous system, both the cyclic voltammogram and the strain curve indicate some minor anion activity, represented by a slight oxidation wave starting approximately $0.3 \mathrm{~V}$ with a corresponding strain minimum at $0.4 \mathrm{~V}$. The charge density calculated from the current density curves showed values of 57 and $97 \mathrm{mC} \mathrm{cm}^{-2}$ in organic and aqueous electrolyte, respectively. The charging/discharging were in balance, which can be seen from the closed cycles in Fig. 2c, indicating that no over-oxidation/over-reduction processes were involved [37].

\subsubsection{Square-wave potential step}

The strains measured for PEDOT:PSS-IPN trilayers in organic and aqueous electrolytes under an applied square-wave potential from 0.65 to $-0.6 \mathrm{~V}$ were compared over a frequency range of $0.0025-0.1 \mathrm{~Hz}$ (Fig. 3a, b). The actuation speed (strain rate) plotted against the diffusion coefficient is shown in Fig. $3 \mathrm{~d}$.

As can be seen in the cyclic voltammetry at $0.005 \mathrm{~Hz}$ and above (Fig. 2a), the strain in the PEDOT:PSS-IPN trilayer in aqueous solution is three times higher ( $2.7 \%$ vs $1 \%$, ) compared to that in organic solution (Fig. 3a). The profiles of the strain curves for the actuators in aqueous and organic LiTFSI electrolyte solutions are qualitatively similar. At applied frequencies from 0.0025 to $0.1 \mathrm{~Hz}$, the strain in the case of both solvents decreases with increasing fre- 

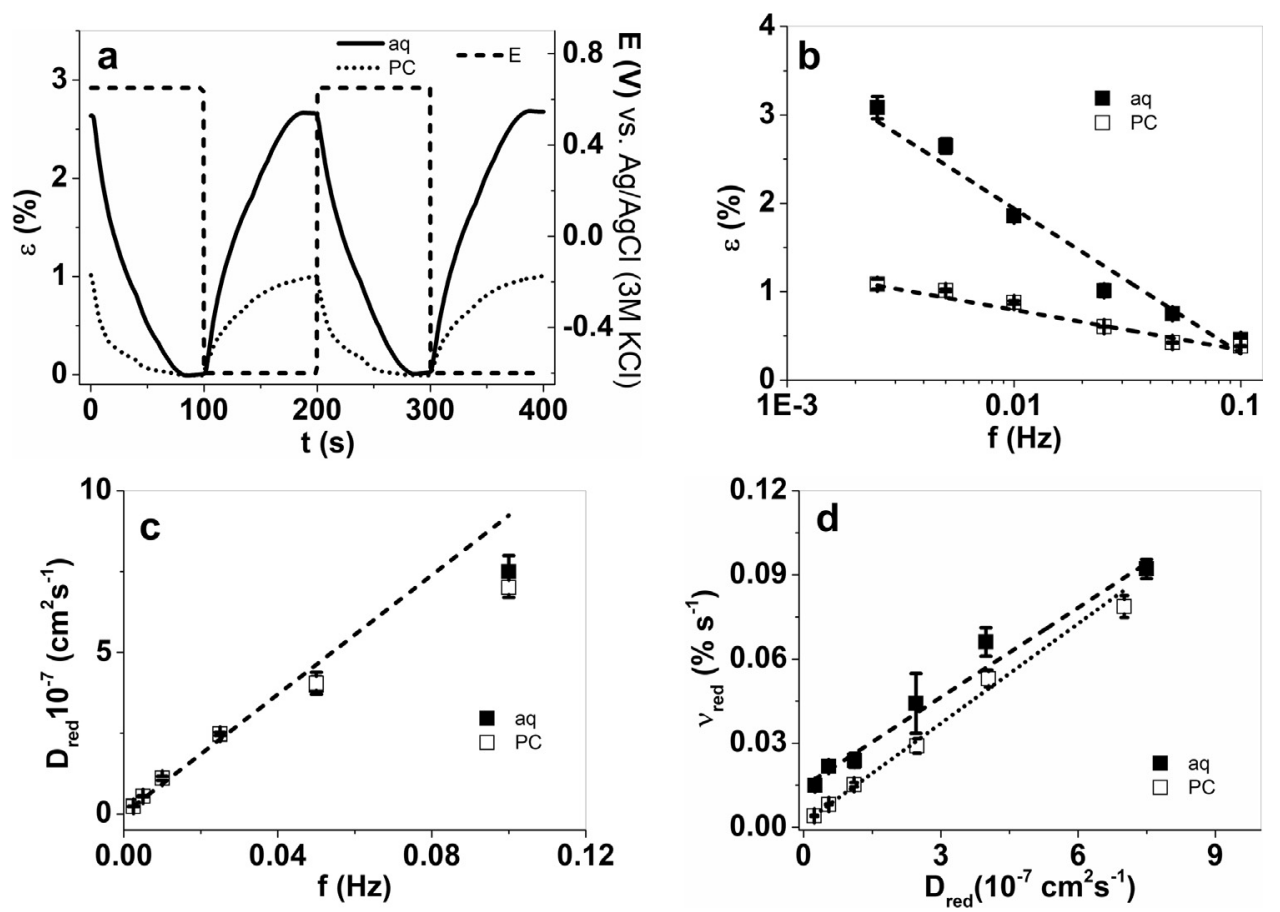

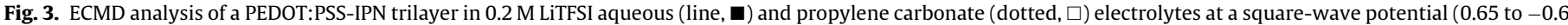

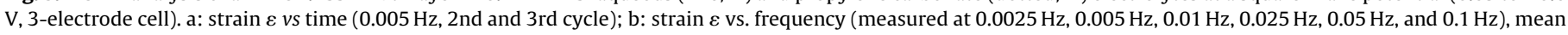

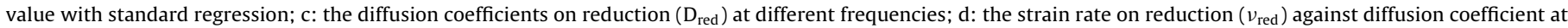
reduction.

quency (Fig. 3b), similar to electrochemically deposited conducting polymers [38]. The charge density at oxidation and reduction of PEDOT:PSS-IPN in the aqueous solution $\left(0.0025 \mathrm{~Hz}, 88 \mathrm{mC} \mathrm{cm}^{-2}\right)$ is nearly double that in the organic solution $\left(47 \mathrm{mC} \mathrm{cm}^{-2}\right)$ (Fig. S1a). The dependency between the strain and the consumed charge (Fig. $\mathrm{S} 1 \mathrm{~b}$ ) is linear in both cases. The correlation between the diffusion coefficients at reduction and the applied frequencies (Fig. 3c) is also linear, with diffusion coefficients increasing with increasing frequency, as expected [39]. Surprisingly, there is no big difference between the diffusion coefficients at reduction in aqueous and propylene carbonate LiTFSI solutions. In both cases, the solvated $\mathrm{Li}^{+}$ ions move into the PEDOT:PSS layer during reduction. The solvation shell of the $\mathrm{Li}^{+}$ions in propylene carbonate has been shown to consist of 3-4 PC molecules [40]; according to the same investigation, $\mathrm{Li}^{+}$ions enter the conducting polymer/electrolyte interface unshelled. In an aqueous system, the hydrophilic nature of PSS leads to significant swelling, and the $\mathrm{Li}^{+}$ions carry 5-6 water molecules with them [41] into the film, leading to higher swelling of the PEDOT:PSS at reduction. The nearly identical diffusion coefficient of $\mathrm{Li}^{+}$ions in aqueous and propylene carbonate solutions indicate that the unswollen PEDOT:PSS in PC offers the same resistance to $\mathrm{Li}^{+}$ion transport as the swollen material in aqueous solution does to the solvated $\mathrm{Li}^{+}$ions. Comparison of the strain rates ( $\left.v_{\text {red }}\right)$ (Fig. 3d) shows that at all applied frequencies, the strain rate in aqueous electrolyte solution is faster than in propylene carbonate. However, the difference in strain rate decreases from 3.7 times to 1.2 times with increasing frequency.

\subsubsection{Chronopotentiometric measurements}

PEDOT:PSS-IPN trilayer linear actuators were characterized by consecutive square-wave currents at frequencies ranging from $0.0025-0.1 \mathrm{~Hz}$. The chronopotentiograms at a frequency of $0.005 \mathrm{~Hz}$ ( 2 consecutive cycles) in aqueous and propylene carbonate solutions are shown in Fig. 4a. The specific capacitance $C_{s}\left(F^{-1}\right)$ of the
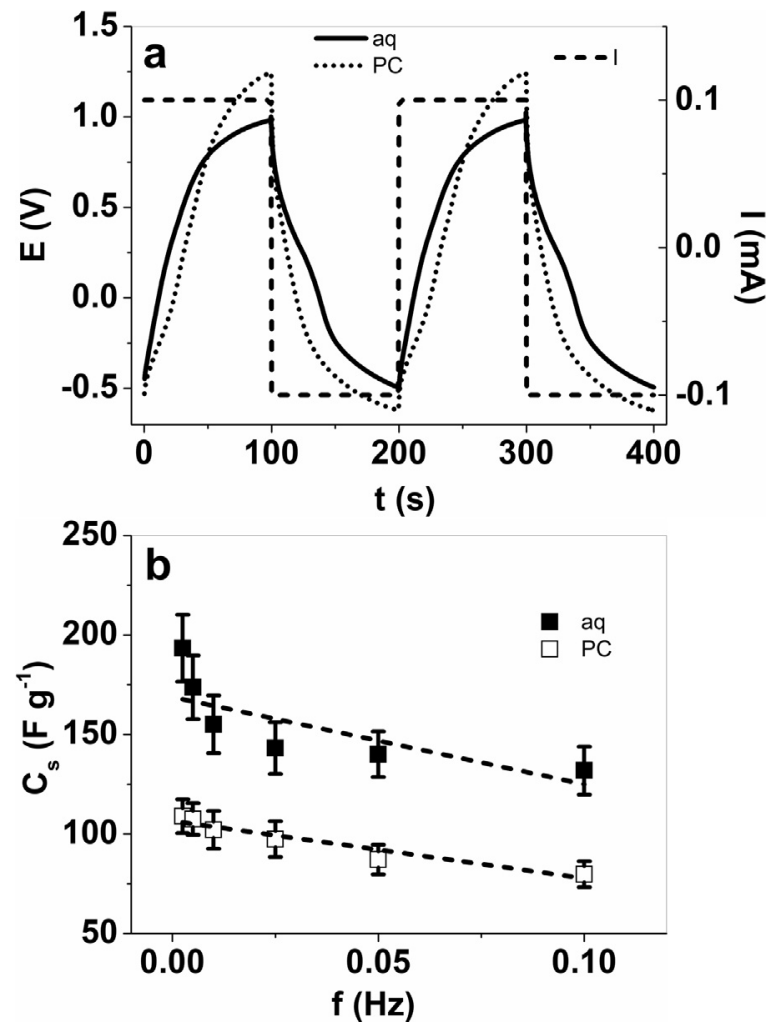

Fig. 4. Chronopotentiograms (charge density of $33 \mathrm{mC} \mathrm{cm}^{-2}$ ) of PEDOT:PSS-IPN trilayers. A: potential vs. time curves in LiTFSI-aq (solid line) and LiTFSI-PC (dotted) at $0.005 \mathrm{~Hz}$ ( 2 subsequent cycles at an applied current of $\pm 0.1 \mathrm{~mA}$ ) and b: the specific capacitance $C_{S}$ against the applied frequency in LiTFSI-aq ( $\square$ ) and LiTFSI-PC ( $\square$ ). 

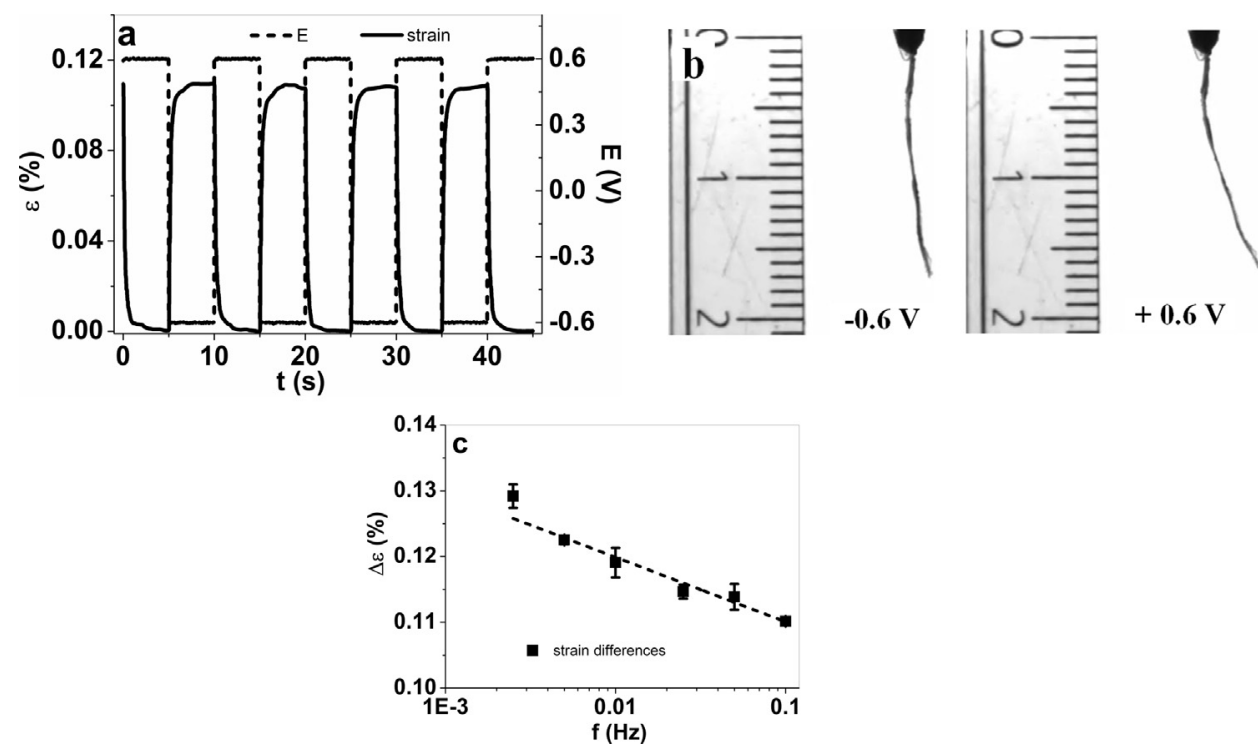

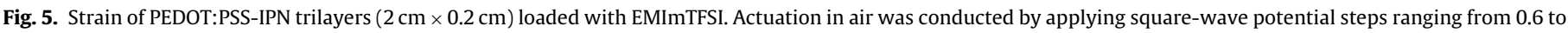

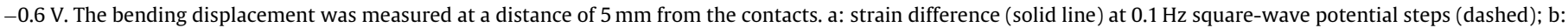
images of the displacement at opposite polarization, c: strain difference vs. frequency.

PEDOT:PSS-IPN was calculated from Eq. (5). The slope is taken from the discharging curve of the potential versus time curves.

$C_{s}=\frac{i}{(- \text { slope } * m)}$

The applied current $i$ and the mass $m$ of the PEDOT:PSS-IPN material were measured, and the slope was obtained from the potential versus time curves for discharging (after IR drop correction)(Fig. 4a) as $\Delta \mathrm{E} / \Delta \mathrm{t}$ [42]. The results are shown in Fig. 4b.

For a square-wave current, the potential curves (Fig. 4a) of the PEDOT:PSS-IPN trilayer in LiTFSI-aq and LiTFSI-PC electrolyte show that the peak potentials at oxidation and reduction are lower in aqueous solvent than in propylene carbonate. The calculated specific capacitances (Eq. (5)) at $0.0025 \mathrm{~Hz}(0.05 \mathrm{~mA})$ were $193.4 \pm 16.8 \mathrm{Fg}^{-1}$ and $109 \pm 11 \mathrm{Fg}^{-1}$ 'in LiTFSI-aq and LiTFSI-PC electrolyte, respectively (Fig. 4b). It has been previously reported that the specific capacitance of PEDOT:PSS mixed with $40 \%$ carbon nanotubes (CNT) reached $133 \mathrm{Fg}^{-1}$ [43]. The specific capacitance of pristine PEDOT:PSS is expected to be in the range of $100 \mathrm{Fg}^{-1}$ [44].

\subsection{PEDOT:PSS-IPN trilayer actuation in air}

The bending strain of a PEDOT:PSS-IPN trilayer in air was analyzed using ionic liquid (EMImTFSI) as the electrolyte (similar to the study of Maziz et al. [15]), drifts related to solvent evaporation were excluded. The strain profile against time $(0.1 \mathrm{~Hz})$ and images of the bending displacement of a PEDOT:PSS-IPN trilayer (videos at $0.1 \mathrm{~Hz}$ and $0.05 \mathrm{~Hz}$, supplementary files, S1 and S2) are shown in Fig. $5 \mathrm{a}$ and b, respectively. For these measurements, a square-wave potential signal in the range of $\pm 0.6 \mathrm{~V}$ was applied at frequencies ranging from $0.1 \mathrm{~Hz}$ to $0.0025 \mathrm{~Hz}$, as shown in Fig. 5c.

The strain of the PEDOT:PSS-IPN trilayer at $0.1 \mathrm{~Hz}$ shows a uniform profile (Fig. 5a), as also seen in the images of the bending displacement (Fig. 5b, video S1, S2). It can be observed that the trilayer bends at reduction and returns to its original position at oxidation. The strain is higher at lower frequencies, but between 0.0025 and $0.1 \mathrm{~Hz}$, the strain decreases only from $0.13 \%$ to $0.11 \%$ (Fig. 5c). The charge density at oxidation/reduction (Fig. S2a) at all measured frequencies except $0.0025 \mathrm{~Hz}$ was found to be in a similar range of $\pm 4-5 \mathrm{mC} \mathrm{cm}^{-2}$. Comparing the charge density curves at $0.0025 \mathrm{~Hz}$ (Fig. S2b) to those of linear actuation in aqueous and organic solutions, it can be observed that in ionic liquid, the charge density is less frequency dependent than in the case of LiTFSI electrolyte solutions. For a PEDOT:PSS polyurethane trilayer in the same ionic liquid [45], the actuation mechanism below $1.5 \mathrm{~V}$ was attributed to an electric double layer (EDL) charging mechanism, which we assume is the reason for the small change in strain in the applied frequency range (Fig. 5c) and the typical capacitor-like behavior observed in the current density versus time curves (Fig. S2a). The frequency response of the strain showed two resonance frequencies (Fig. S3) at $11 \mathrm{~Hz}(0.04 \%)$ and $44 \mathrm{~Hz}(0.004 \%)$.

\section{Conclusion}

Inkjet-printed PEDOT:PSS $(2.2 \mu \mathrm{m})$ deposited on both sides of spin-coated films of semi-IPN (NBR/PEO) formed electromechanically active trilayers with a combined thickness of $12.7 \mu \mathrm{m}$; using semi-IPN as a membrane, the trilayer showed improved strain response in linear actuation mode and confirmed also effective application in bending mode. The printed PEDOT-PSS electrodes with a high conductivity of $190 \mathrm{~S} \mathrm{~cm}^{-1}$ led to a specific capacity as high as $193 \mathrm{Fg}^{-1}$. In the linear actuation mode, involving mainly a cation-driven faradaic charging mechanism, the composite showed a strain of $3 \%$ and $1 \%$ in $0.2 \mathrm{M}$ LiTFSI aqueous and propylene carbonate solutions, respectively. The actuation of a PEDOT:PSS-IPN trilayer with a room temperature ionic liquid EMImTFSI as the electrolyte followed an EDL charging mechanism. The use of a scalable and consistent processing technology in the form of ink-jet printed PEDOT:PSS on thin spin-coated IPN membranes opens up novel opportunities for the mass production of linear and bending actuators with potential applications in energy storage.

\section{Acknowledgements}

The research was supported by the European Union's Horizon 2020 research and innovation programme under the Marie Sklodowska-Curie grant agreement No. 641822, by the Estonian Science Foundation (Grant No. IUT20-24 and Grant No. PUT1696) and Hubert Curien French-Estonian collaboration programme "G. F. Parrot". 


\section{Appendix A. Supplementary data}

Supplementary data associated with this article can be found, in the online version, at https://doi.org/10.1016/j.snb.2017.11.147.

\section{References}

[1] G. Alici, A. Punning, H.R. Shea, Enhancement of actuation ability of ionic-type conducting polymer actuators using metal ion implantation, Sens. Actuators B Chem. 157 (2011) 72-84, http://dx.doi.org/10.1016/j.snb.2011.03.028.

[2] T. Sugino, K. Kiyohara, I. Takeuchi, K. Mukai, K. Asaka, Actuator properties of the complexes composed by carbon nanotube and ionic liquid: the effects of additives, Sens. Actuators, B Chem. 141 (2009) 179-186, http://dx.doi.org/10. 1016/j.snb.2009.06.002.

[3] N. Terasawa, K. Yamato, Comparison of electrochemical and electromechanical properties of a high performance carbon black polymer actuator and a single-walled carbon nanotube polymer actuator, Sens. Actuators B Chem. 176 (2013) 1103-1109, http://dx.doi.org/10.1016/j.snb. 2012.10.103.

[4] H. Lian, W. Qian, L. Estevez, H. Liu, Y. Liu, T. Jiang, et al., Enhanced actuation in functionalized carbon nanotube-Nafion composites, Sens. Actuators B Chem. 156 (2011) 187-193, http://dx.doi.org/10.1016/j.snb.2011.04.012.

[5] N. Aydemir, T. Tamm, J. Travas-Sejdic, P.A. Kilmartin, A. Aabloo, R. Kiefer, Electrochemomechanical Deformation (ECMD) of PPyDBS in Free Standing Film Formation and Trilayer Designs, 9056, 2014, pp. 905631, http://dx.doi. org/10.1117/12.2044702.

[6] K. Uh, B. Yoon, C.W. Lee, J.M. Kim, An electrolyte-free conducting polymer actuator that displays electrothermal bending and flapping wing motions under a magnetic field, ACS Appl. Mater. Interfaces 8 (2016) 1289-1296, http://dx.doi.org/10.1021/acsami.5b09981.

[7] L.J. Romasanta, M.A. Lopez-Manchado, R. Verdejo, Increasing the performance of dielectric elastomer actuators: a review from the materials perspective, Prog. Polym. Sci. 51 (2015) 188-211, http://dx.doi.org/10.1016/j. progpolymsci.2015.08.002.

[8] S.A. Wilson, R.P.J. Jourdain, Q Zhang, R. a Dorey, C.R. Bowen, M. Willander, et al., New materials for micro-scale sensors and actuators An engineering review, Mater. Sci. Eng. R. Rep. 56 (2007) 1-129, http://dx.doi.org/10.1016/j. mser.2007.03.001.

[9] I. Põldsalu, S.-E. Mändmaa, A.-L. Peikolainen, A. Kesküla, A. Aabloo, Fabrication of ion-conducting carbon polymer composite electrodes by spin coating, in: Proc. SPIE 9430. Electroact. Polym. Actuators Devices 2015, SPIE, 2015, 2017. p. 943019, http://dx.doi.org/10.1117/12.2084180.

[10] A. Simaite, F. Mesnilgrente, B. Tondu, P. Souères, C. Bergaud, Towards inkjet printable conducting polymer artificial muscles, Sens. Actuators B Chem. 229 (2016) 425-433, http://dx.doi.org/10.1016/j.snb.2016.01.142.

[11] R. Kiefer, R. Temmer, T. Tamm, J. Travas-Sejdic, P.A. Kilmartin, A. Aabloo Conducting polymer actuators formed on MWCNT and PEDOT-PSS conductive coatings, Synth. Met. 171 (2013) 69-75, http://dx.doi.org/10.1016/j.synthmet. 2013.03.017.

[12] N. Festin, A. Maziz, C. Plesse, D. Teyssié, C. Chevrot, F. Vidal, Robust solid polymer electrolyte for conducting IPN actuators, Smart Mater. Struct. 22 (2013) 104005, http://dx.doi.org/10.1088/0964-1726/22/10/104005.

[13] J. Zhou, M. Mulle, Y. Zhang, X. Xu, E.Q. Li, F. Han, et al., High-ampacity conductive polymer microfibers as fast response wearable heaters and electromechanical actuators, J. Mater. Chem. C 4 (2016) 1238-1249, http://dx. doi.org/10.1039/C5TC03380B.

[14] E.W.H. Jager, E. Smela, O. Inganäs, I. Lundström, Polypyrrole micro actuators, Synth. Met. 102 (1999) 1309-1310, http://dx.doi.org/10.1016/S03796779(98)01000-5.

[15] A. Maziz, C. Plesse, C. Soyer, C. Chevrot, D. Teyssié, E. Cattan, et al., Demonstrating $\mathrm{kHz}$ frequency actuation for conducting polymer microactuators, Adv. Funct. Mater. 24 (2014) 4851-4859, http://dx.doi.org/10. 1002/adfm.201400373.

[16] A. Khaldi, A. Maziz, G. Alici, G.M. Spinks, E.W.H. Jager, Bottom-up microfabrication process for individually controlled conjugated polymer actuators, Sens. Actuators B Chem. 230 (2016) 818-824, http://dx.doi.org/10 1016/j.snb.2016.02.140.

[17] A. Khaldi, C. Plesse, C. Soyer, E. Cattan, F. Vidal, C. Legrand, et al., Conducting interpenetrating polymer network sized to fabricate microactuators, Appl. Phys. Lett. 98 (2011) 10-13, http://dx.doi.org/10.1063/1.3581893.

[18] H. Okuzaki, Soft and Flexible PEDOT/PSS Films for Applications to Soft Actuators, 74010, 2017, pp. 25-26, http://dx.doi.org/10.1088/0964-1726/23/ $7 / 074010$.

[19] I. Must, F. Kaasik, I. P??ldsalu, L. Mihkels, U. Johanson, A. Punning, et al., Ionic and capacitive artificial muscle for biomimetic soft robotics, Adv. Eng. Mater. 17 (2015) 84-94, http://dx.doi.org/10.1002/adem.201400246.

[20] K. Ikushima, S. John, A. Ono, S. Nagamitsu, PEDOT/PSS bending actuators for autofocus micro lens applications, Synth. Met. 160 (2010) 1877-1883, http:// dx.doi.org/10.1016/j.synthmet.2010.07.003.

[21] M. Hiraoka, P. Fiorini, J. O’Callaghan, I. Yamashita, C. Van Hoof, M. Op De Beeck, Miniature conductive polymer actuators for high pressure generation in lab on chip systems, Sens. Actuators A Phys. 177 (2012) 23-29, http://dx. doi.org/10.1016/j.sna.2011.08.024.
[22] T.F. Otero, J.M. Sansiñena, Artificial muscles based on conducting polymers, Bioelectrochem. Bioenergy 38 (1995) 411-414, http://dx.doi.org/10.1016/ 0302-4598(95)01802-L.

[23] E. Smela, Conjugated polymer actuators for biomedical applications, Adv. Mater. 15 (2003) 481-494.

[24] E.W.H. Jager, E. Smela, O. Inganäs, Microfabricating conjugated polymer actuators, Science 290 (2000) 80, http://science.sciencemag.org/content/290 5496/1540.full (Accessed 4 September 2017).

[25] R. Temmer, A. Maziz, C. Plesse, A. Aabloo, F. Vidal, T. Tamm, In search of bette electroactive polymer actuator materials: PPy versus PEDOT versus PEDOT-PPy composites, Smart Mater. Struct. 22 (2013) 104006, http://dx.doi org/10.1088/0964-1726/22/10/104006.

[26] O. Andruchov, O. Andruchova, S. Galler, The catch state of mollusc catch muscle is established during activation: experiments on skinned fibre preparations of the anterior byssus retractor muscle of Mytilus edulis L. using the myosin inhibitors orthovanadate and blebbistatin, J. Exp. Biol. 209 (2006) 4319-4328, http://dx.doi.org/10.1242/jeb.02501.

[27] N. Festin, C. Plesse, P. Pirim, C. Chevrot, F. Vidal, Electro-active Interpenetrating Polymer Networks actuators and strain sensors: fabrication, position control and sensing properties, Sens. Actuators B Chem. 193 (2014) 82-88, http://dx.doi.org/10.1016/j.snb.2013.11.050.

[28] A. Maziz, C. Plesse, C. Soyer, E. Cattan, F. Vidal, Top-down approach for the direct synthesis, patterning, and operation of artificial micromuscles on flexible substrates, ACS Appl. Mater. Interfaces 8 (2016) 1559-1564, http://dx. doi.org/10.1021/acsami.5b09577.

[29] I. Põldsalu, M. Harjo, T. Tamm, M. Uibu, A.-L. Peikolainen, R. Kiefer, Inkjet-printed hybrid conducting polymer-activated carbon aerogel linear actuators driven in an organic electrolyte, Sens. Actuat B Chem. 250 (2017) 44-51, http://dx.doi.org/10.1016/j.snb.2017.04.138.

[30] C.J. Lawrence, The mechanics of spin coating of polymer films, Phys. Fluids 31 (1988) 2786, http://dx.doi.org/10.1063/1.866986.

[31] A. Kivilo, Z. Zondaka, A. Kesküla, P. Rasti, T. Tamm, R. Kiefer, Electro-chemo-mechanical deformation properties of polypyrrole/dodecylbenzenesulfate linear actuators in aqueous and organic electrolyte, RSC Adv. 6 (2016) 69-75, http://dx.doi.org/10.1039/C6RA20766A.

[32] T.F. Otero, J.G. Martinez, Activation energy for polypyrrole oxidation: film thickness influence, J. Solid State Electrochem. 15 (2011) 1169-1178, http:// dx.doi.org/10.1007/s10008-010-1170-1.

[33] Heraeus Technical Service Information, (n.d.). https:/www.heraeus.com/en/ group/products_and_solutions_group/conductive_polymers/technical_service_ information/technical-service-information.aspx (Accessed 8 August 2017).

[34] Y. Zhou, F. Zhang, K. Tvingstedt, S. Barrau, F. Li, W. Tian, et al., Investigation on polymer anode design for flexible polymer solar cells, Appl. Phys. Lett. 92 (2008) 92-94, http://dx.doi.org/10.1063/1.2945796.

[35] N. Aydemir, P.A. Kilmartin, J. Travas-Sejdic, A. Kesküla, A.L. Peikolainen, J. Parcell, et al., Electrolyte and solvent effects in PPy/DBS linear actuators, Sens. Actuators B Chem. 216 (2015) 24-32, http://dx.doi.org/10.1016/j.snb.2015.03. 098.

[36] T. Raudsepp, M. Marandi, T. Tamm, V. Sammelselg, J. Tamm, Study of the factors determining the mobility of ions in the polypyrrole films doped with aromatic sulfonate anions, Electrochim. Acta 53 (2008) 3828-3835, http://dx. doi.org/10.1016/j.electacta.2007.11.059.

[37] L. Valero, T.F. Otero, J.G. Martinez, J.G. Martínez, Exchanged cations and water during reactions in polypyrrole macroions from artificial muscles, ChemPhysChem 15 (2014) 293-301, http://dx.doi.org/10.1002/cphc. 201300878.

[38] R. Kiefer, A. Kesküla, J.G. Martinez, G. Anbarjafari, J. Torop, T.F. Otero, Electrochimica acta Interpenetrated triple polymeric layer as electrochemomechanical actuator: solvent influence and diffusion coefficient of counterions, Electrochim. Acta 230 (2017) 461-469, http://dx.doi.org/10. 1016/j.electacta.2017.01.191

[39] P. Giménez, K. Mukai, K. Asaka, K. Hata, H. Oike, T.F. Otero, Capacitive and faradic charge components in high-speed carbon nanotube actuator, Electrochim. Acta 60 (2012) 177-183, http://dx.doi.org/10.1016/j.electacta. 2011.11.032.

[40] P.M. Dziewoński, M. Grzeszczuk, Impact of the electrochemical porosity and chemical composition on the lithium ion exchange behavior of polypyrroles (ClO4\n-, TOS-, TFSI-) prepared electrochemically in propylene carbonate. Comparative EQCM, EIS and CV studies, J. Phys. Chem. B 114 (2010) 7158-7171, http://dx.doi.org/10.1021/jp100796a.

[41] G. Orädd, L. Edman, A. Ferry, Diffusion: a comparison between liquid and solid polymer LiTFSI electrolytes, Solid State Ionics 152-153 (2002) 131-136, http://dx.doi.org/10.1016/S0167-2738(02)00364-8.

[42] M. Plaado, F. Kaasik, R. Valner, E. Lust, R. Saar, K. Saal, et al., Electrochemical actuation of multiwall carbon nanotube fiber with embedded carbide-derived carbon particles, Carbon N. Y. 94 (2015) 911-918, http://dx.doi.org/10.1016/j. carbon.2015.07.077.

[43] D. Antiohos, G. Folkes, P. Sherrell, S. Ashraf, G.G. Wallace, P. Aitchison, et al., Compositional effects of PEDOT-PSS/single walled carbon nanotube films on supercapacitor device performance, J. Mater. Chem. 21 (2011) 15987, http:// dx.doi.org/10.1039/c1jm12986d.

[44] S. Ghosh, O. Inganäs, Conducting polymer hydrogels as 3D electrodes: applications for supercapacitors, Adv. Mater. 11 (1999) 1214-1218.

[45] Y. Li, R. Tanigawa, H. Okuzaki, Soft and fl exible PEDOT/PSS films for applications to soft actuators, Smart Mater. Struct. 23 (2014) 074010-074018, http://dx.doi.org/10.1088/0964-1726/23/7/074010. 


\section{Biographies}

Inga Põldsalu was born in 1988 in Tallinn, Estonia. She received her master's degree in materials science from University of Tartu. Presently she is working on her doctorate studies in physical engineering, mainly focusing on developing microfabrication technologies for ion conducting electromechanically active materials.

Kätlin Rohtlaid graduated from Tallinn University of Technology and earned bachelor degree in technology of materials. Then she continued her studies in University of Tartu and worked with conducting polymer actuators. After finishing her master's degree in materials science in 2015, she joined LPPI (Laboratoire de Physicochimie des Polymères et des Interfaces) laboratory in Université de Cergy Pontoise. The goal of her work is to fabricate conducting IPN microactuators and integrate them into microsystems.

Giao T. M. Nguyen received her PhD degree in 2003 on Chemistry and Physicochemistry of Polymer from University of Maine (France). She then joined Prof. Bo Nyström's group in Oslo University (Norway) as a postdoctoral fellow (2004-2005) working on the modification of polysaccharides. In 2008, she joined LPPI as temporary assistant professor and then as postdoctoral fellow (2009-2010). She is permanent assistant professor since 2010. Her current interests focus on (1) the synthesis of polymer network for using as supporting matrix of flexible electrochemical devices such as actuators, supercapacitors, (2) the elaboration of electrochemical devices and (3) the synthesis of new electrolyte polymer systems pour batteries and supercapacities.

Cedric Plesse received his $\mathrm{PhD}$ (2004) degree in Polymer Chemistry from Cergy-Pontoise University. His research focused on conducting polymer based Interpenetrating Polymer Networks (IPN) to develop electrochemical actuators. He joined Prof. Mario Leclerc's group in Laval University (Quebec, Canada) as a postdoctoral fellow (2004-2006) working on the development of conducting polymers based DNA sensors. He joined LPPI at the University of Cergy-Pontoise as an assistant professor in 2006. His research currently deals with pi-conjugated molecular glasses for hybrid photovoltaic devices and conducting IPN based actuators, from material synthesis to electrochemomechanical characterizations on a macro and micro scale.
Frederic Vidal received his $\mathrm{PhD}$ (1995) degree on Polymer Chemistry from Lyon University. He then joined Prof. German's group in Eindhoven Technology University as a postdoctoral fellow (1995-1996). His interest focused on the emulsion polymerization. He joined Cergy-Pontoise University as an associate professor in 1997 in the laboratory of Prof. D. Teyssié and C. Chevrot ad he was appointed as a full Professor in 2008. His research currently includes development of Interpenetrating Polymer Networks (IPNs), conducting polymer and conducting IPN based electrochemical devices such as electrochromic devices or actuators.

Mahdi Safaei Khorram received his BSc in 2001 in Green Chemistry. His MSc and $\mathrm{PhD}$ in Environmental Chemistry granted in 2012 and 2016 from Gothenburg University (sweden) and Zhejiang University (China), respectively. He has worked in Ton Duc Thang University as a lecturer and researcher from 2016 to 2017, and now he is a postdoctoral researcher in Chinese Academy of Science (Guangzhou, China).

Anna-Liisa Peikolainen obtained her PhD degree in 2011 in chemistry at the Tallinn University of Technology. Her main research topic was nanoporous organic aerogels. Organic aerogel being one of the sources of high surface area carbon led her to field of carbon based actuators. Since 2012 she is a research fellow in materials technology in the Intelligent Materials and Systems Lab at the University of Tartu focusing on carbon-polymer composites and carbon based actuators.

Tarmo Tamm, born in Tartu, Estonia, received both his MSc and PhD degrees in chemistry at the University of Tartu. At present, he is a senior research fellow of material sciences at the University of Tartu, Estonia. His research interests are mainly related to both the experimental and theoretical characterization of materials, especially conducting polymers.

Rudolf Kiefer received his MSc diploma in chemistry in 1999 and his PhD degree (conducting polymers for micro actuators) in micro system techniques in 2005 from the University of Freiburg, Germany. He made his post-doc at the Polymer Electronic Research Centre (PERC) of University of Auckland, New Zealand, worked in Industrial Technology Research Institute in Hsinchu, Taiwan, as a researcher, and in the University of Tartu (Estonia) as a visiting professor and senior research fellow. Since 2016 he is an associate professor at Ton Duc Thang University, Vietnam. His main research interest include characterization and applications of electroactive polymers. 